\title{
OPTIMIZATION OF A NUMBER OF CONTAINERS FOR ASSEMBLY LINES: THE FIXED-COURSE PICK-UP SYSTEM
}

\author{
Nomura, J. \& Takakuwa, S. \\ Nagoya University, Graduate School of Economics and Business Administration, \\ Furo, Chikusa, Nagoya, 464-8601, Japan \\ E-Mail: jun_n@nifty.com; takakuwa@soec.nagoya-u.ac.jp
}

\begin{abstract}
A heuristic procedure is proposed to determine the optimal number of containers holding parts used on the assembly lines. A complex number of piece parts are supplied in terms of a fixed-course pick-up system. The carrier travels between a parts-storages area and the assembly lines repeatedly; hence it is called "Mizusumashi" (the whirligig beetle). On the assembly lines, the parts-container is put on racks so that the operator may pick up the specific parts to assemble products. The characteristics of the Mizusumashi system are described and the equation to obtain the expected number of parts-container size is presented. From this, a heuristic procedure using simulation to determine the optimal number of partscontainer is proposed. In addition, this procedure is applied to a real manufacturing system, and the proposed procedure is found to be effective and powerful especially from the practical standpoint.

(Received in February 2006, accepted in November 2006. This paper was with the authors 3 months for 2 revisions.)
\end{abstract}

Key Words: Just-In-Time Manufacturing, Optimization, Heuristics, Work-In-Process Inventory, Mizusumashi (Fixed-Course Pick-Up) System

\section{INTRODUCTION}

The developers of the just-in-time (JIT) concepts often utilize the Mizusumashi system as well as the Kanban system. The Kanban system has been widely used in the world [1-8]. Simulation analysis was performed for the Kanban system (for example, [9]). The fixedcourse pick-up (Mizusumashi system) is one of the popular means of realizing the manufacturing philosophy of JIT manufacturing used to produce or retrieve the required amount of necessary items at the right time. Workers move between assembly lines and storages for parts regularly and bring the required amount of necessary types of parts onto the line. Such workers are called Mizusumashi in the context of popular Japanese production system, that is, the Toyota production system (TPS), also known as JIT manufacturing system [9].

In the mid-1950s, the Mizusumashi system originally played a role of transferring requirements for production, including raw materials, components and parts between factories. As the TPS developed and spread across to other companies and industries, the Mizusumashi system expanded as well to assist in the supplying of materials onto the shop floor. Today, their operations become quite important, as the product life cycle become much shorter and the company executives recognize that unnecessarily large number of inventories might be wasteful.

This study focuses on the work-in-process inventory and supplying parts to their designated assembly lines manually on the shop floor, by utilizing the Mizusumashi system. Mizusumashi are the workers who supply parts or goods to assembly lines with their hands or human-powered carts. Therefore, the Mizusumashi system plays an important role in 
manufacturing partially because it has more flexible characteristics than an automated partssupply system.

In this study, a simulation model for a real manufacturing system using the Mizusumashi system for supplying parts to assembly lines is constructed, especially for the specific handling operations of a Mizusumashi worker. Then, a heuristic procedure together with simulation experiments is proposed to determine the minimal number of containers for the parts. In addition, the proposed procedure is applied to a manufacturing system to confirm its effectiveness from a practical standpoint.

\section{PARTS SUPPLY BY ADOPTING THE MIZUSUMASHI SYSTEM}

The methods for parts supply on the shop floor can be classified into two categories: manualbased and automated-based supply system. The former is a system in which workers supply parts with their hands or human-powered carts, as represented by the Mizusumashi system. The latter is a system adopting such more technical materials-handling equipment as automated guided vehicles (AGVs) and conveyors to transfer goods among processes and storages. In the automated system, it would be hard to reconfigure its layout at a lower cost. Therefore, the manually-based parts-supply system would be better suited for such industries that often change the kinds of products made or the layout of the shop floor in accordance with the sales, because such a system is more flexible than the automated-based one in the view of adaptation to change the contents of works.

Moreover, the purposes for performing a simulation analysis are different between these two systems. For the automated system, simulation experiments are often performed at the planning phase to determine its system configuration. On the other hand, the manual system typically utilizes simulation in order to determine a method of performing works more effectively, considering environmental changes of production.

A Mizusumashi worker or carrier performs operations of supplying parts to designated assembly lines with their hands or human-powered carts. There are two methods for supply parts as performed by Mizusumashis. One method is called a periodic reviewing method, and the other is a ceaseless reviewing method. In supplying parts by using the periodic reviewing, a Mizusumashi checks the amount of parts of the work-in-process inventories at the assembly lines in a predetermined time interval, and replenishes the number of parts corresponded to the capacity of the parts-container that the worker picked up at the last time. As for the ceaseless reviewing method, the time-point of replenishing and checking parts occurs simultaneously; a Mizusumashi checks parts of the work-in-process inventory for the next replenishment at the time when the worker completes supplying of parts corresponding to the previous reviewing. Therefore, a Mizusumashi always moves around on the shop floor in the latter method, while the worker waits until the next review time arrives after the last parts supply has finished in the former one.

The typical workflow of a Mizusumashi is shown in Fig. 1. First, a Mizusumashi checks the number of parts used since the last reviewing time. In general, parts are set in a container to ease for the handling and counting. A capacity of a parts-container is usually defined by a purchasing contract between a parts supplier and a manufacturer, and can not be controlled by the operators at the shop floor level. A Mizusumashi only picks up empty containers and not a container with remaining parts. Therefore, the number of containers for a specific kind of parts at an assembly line generally is more than two.

After reviewing all parts on the assembly lines, a Mizusumashi goes to the associated parts-storages area and fills the empty containers that the worker has picked up at the assembly lines. Finally, a Mizusumashi comes back to the assembly lines and supplies the required containers on the specified rack along the line. At this point, the worker goes to the 
staging area to wait until the next reviewing time, and the workflow is resumed in the same manner of operations at the next reviewing time. In Fig. 1, the dotted-line rectangle indicates the work only carried out during the periodic reviewing, and the solid-line rectangles indicate the works for both review methods. In the same way, the dotted arrows represent paths that only follow in the periodic reviewing, and all Mizusumashi follow solid-line arrows. A typical routing of a Mizusumashi followed in the above-mentioned workflow process is illustrated in Fig. 2.

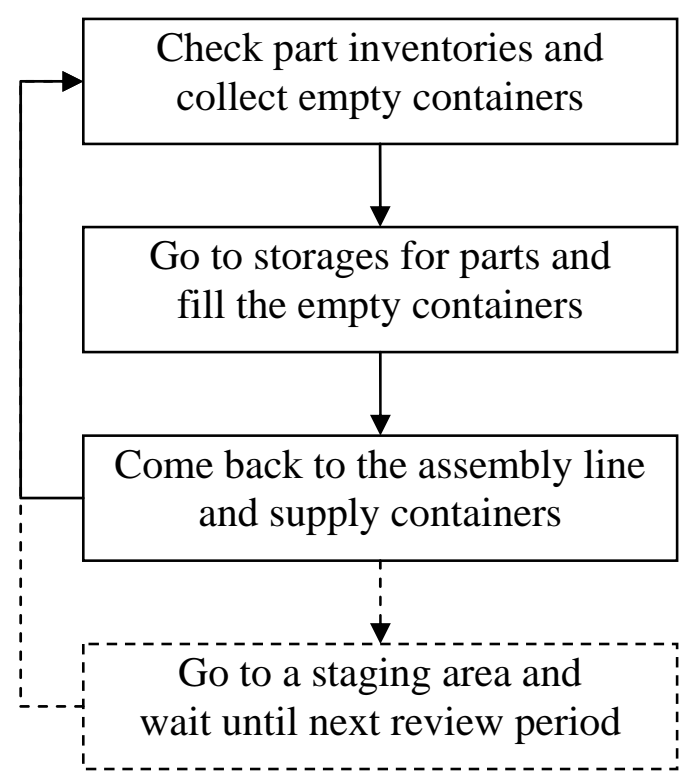

Figure 1: Workflow of a Mizusumashi carrier.

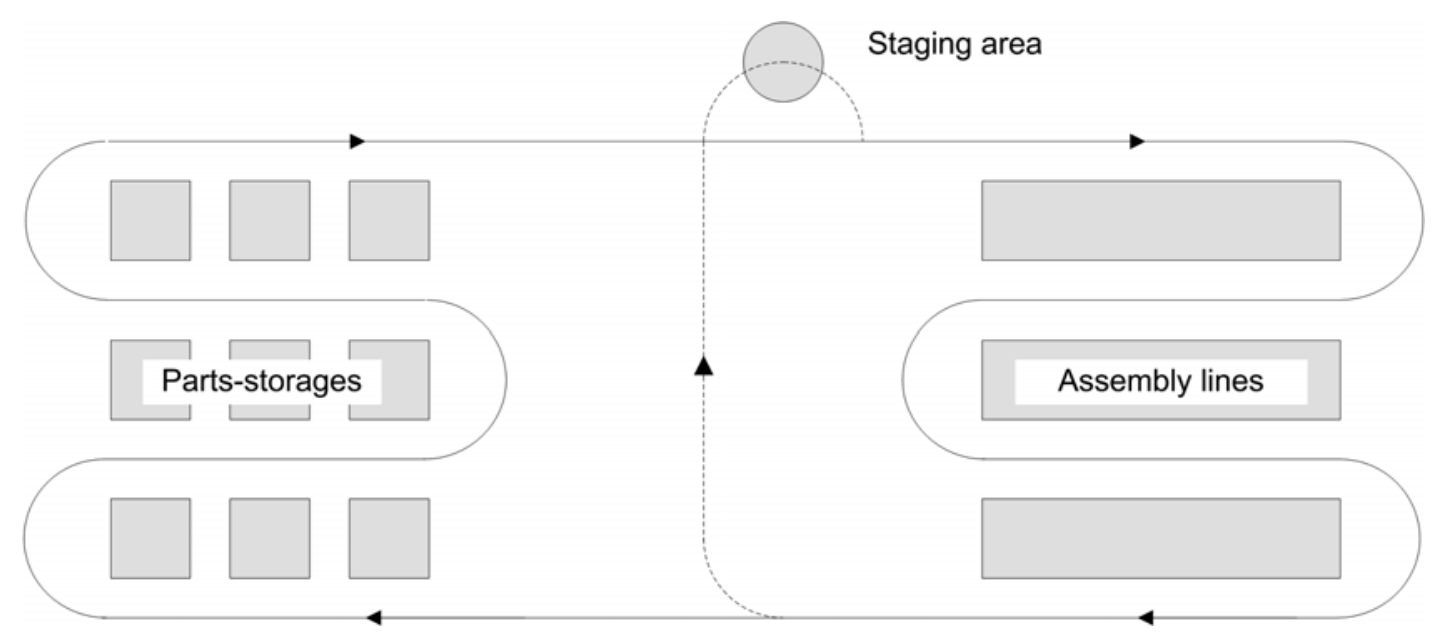

Figure 2: Routing of a Mizusumashi carrier.

Next, the relationship between the part inventories and the replenishment is illustrated at Fig. 3. This figure illustrates the periodic review method or the replenishment system in terms of the inventory system, and there are at most four containers with a capacity of five parts. It is assumed that this system starts with a full or maximal parts inventory, that is, there are four containers with five parts each. In addition, it is assumed that the time interval for reviewing is 20 minutes. At the first reviewing time, there are two empty containers when a Mizusumashi checks the status of the inventory. Hence, the worker picks up the two empty containers and then goes to the parts-storages area for replenishment, and fills the containers. 
After this, the worker comes back to the assembly line and supplies the two filled containers. For this review period, it takes about 10 minutes for the Mizusumashi to perform these consecutive activities and typically waits for another 10 minutes until the next reviewing time. After a period of 40 minutes, the second reviewing period will have started. At this moment, only one container comes out and is to be supplied 8 minutes later.

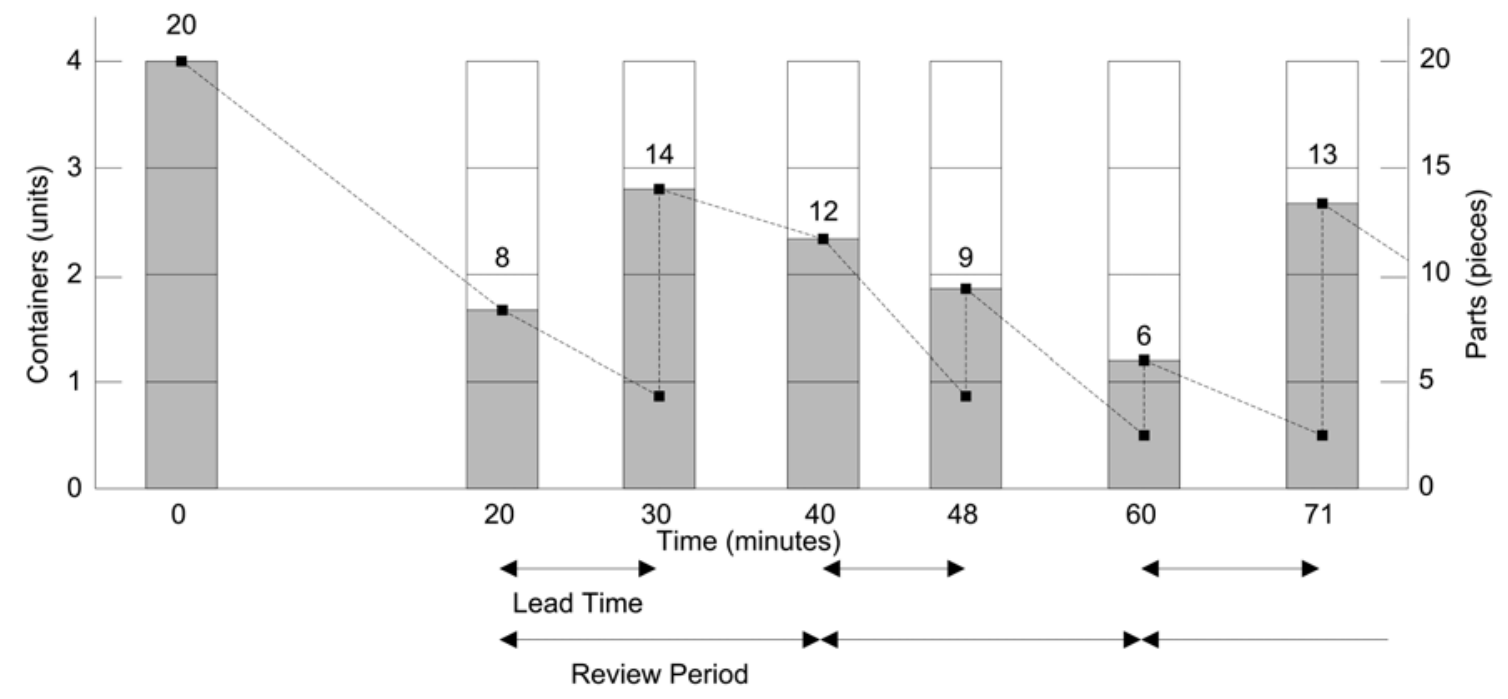

Figure 3: Inventory level with the periodic review method.

As shown in Fig. 3, it is observed that it is important to install an appropriate number of parts-containers for smooth production. If there were not enough number of parts-containers, the operations would frequently stop due to parts shortages. On the other hand, keeping an excessive number of containers would lead to an unnecessarily large work-in-process inventory on the rack at the assembly line. By considering the replenishment system of inventory control [11], the expected number of containers, $M^{E}$, can be given by:

$$
M_{i j}^{E}=\left[\frac{X_{i}+E\left(L_{i j}\right)}{E\left(d_{i}\right) N}\right]+1
$$

where

$d_{j} \quad$ : production speed at assembly line $j$ (sec.)

$i \quad:$ ID number for Mizusumashi $(i=1,2, \ldots, R)$

$j \quad$ : line number designated for Mizusumashi $i\left(j=1,2, \ldots, S_{i}\right)$

$L_{i j} \quad$ : lead time to supply parts into assembly line $j$ by Mizusumashi $i$ (sec.)

$N$ : capacity for container of parts (pieces)

$R \quad$ : the number of Mizusumashi workers in the system

$S_{i} \quad$ : total number of assembly lines allocated to Mizusumashi $i$

$X_{i} \quad$ : review period for Mizusumashi $i$ (sec.)

[a] : function to round real number $a$ down to the nearest integer

The portion of function [ ] in (1) represents that the number of containers must be held during one review period and lead time. As the amount of containers calculated by function [ ] must be raised to the next whole number, it is added by one container in (1). Because a Mizusumashi worker does not usually supply the same parts, the lead time between checking inventories and supplying parts varies each time. Therefore, the dispersion of the lead time of the Mizusumashi worker should be considered, by adding the safety stock to the expected number of containers given by (1). Now, letting the safety stock at the assembly line $j$ by 
Mizusumashi $i$ as $s_{i j}$, the minimal number of containers not causing a shortage of the designated part at the assembly line, $M^{T}$, can be expressed by:

$$
M_{i j}^{T}=\left[\frac{X_{i}+E\left(L_{i j}\right)}{E\left(d_{i}\right) N}+s_{i j}\right]+1
$$

In order to find the optimal number of containers, a heuristics approach using simulation is proposed and illustrated.

\section{A REAL MANUFACTURING SYSTEM}

A real manufacturing system adopting a fixed-course pick-up (Mizusumashi) system was used to illustrate the proposed procedure in the following section.

\subsection{System Overview}

The schematic layout of the system studied in this paper is shown in Fig. 4. Three kinds of products on personal computers were assembled in the manufacturing system. A total sort of parts for assembling these three products is sum up to 95 kinds excluding the same parts. Three breaks (55 minutes in total) were also allowed during a 7.5 hour working-day during operations at the factory. When a break has begun, all workers including Mizusumashi carriers take a rest and the associated assembly lines stop processing.

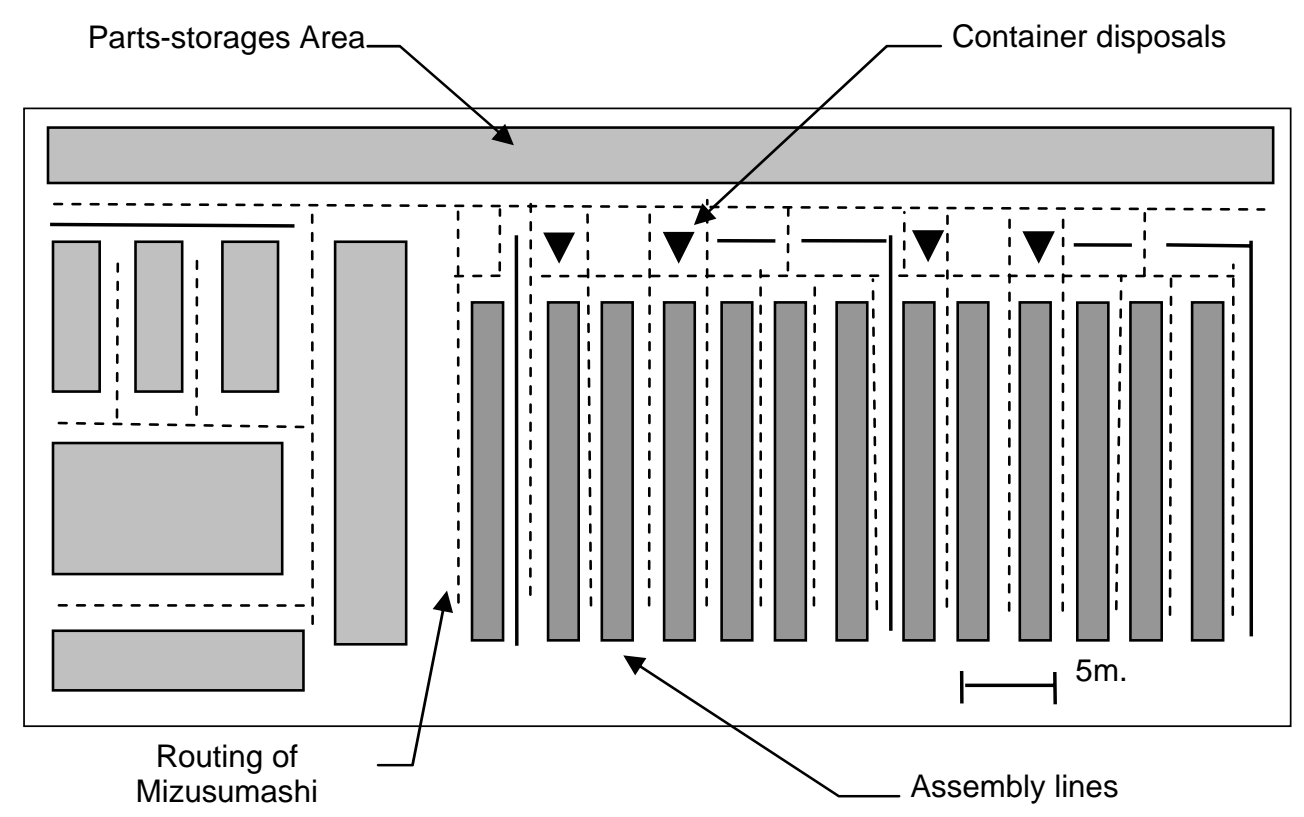

Figure 4: Layout of the system.

\subsection{Irregular Operations for a Mizusumashi}

The periodic review method for a Mizusumashi is adopted to supply parts, but the carriers sometimes perform irregular operations which are not included in the common workflow described in Section 2. These irregular operations include disposing the empty containers of the cardboard box into the waste container bins. In general, parts-containers are made of plastic and can be reusable, and would be preferable to utilize reusable containers in order to 
reduce waste in from view of environmental conservation. Therefore, the company executives mount an effort to switch from cardboard boxes to reusable plastic containers, however some kinds of parts are still set in cardboard boxes. For this reason, if a Mizusumashi has empty containers made by cardboard, the worker must dispose of them in the container disposals shown in Fig. 4 by the triangle shape. This operation is performed on the way to the partsstorages area between the first box and the second one shown in Fig. 1.

\section{SIMULATION MODEL}

A time study was performed to the manufacturing system illustrated in the previous section in order to obtain the data for a series of operation time for a Mizusumashi, including the filling time, supply time and disposal time. The overall required system parameters are summarized in Table I.

Table I: Overall system parameters.

\begin{tabular}{|c|c|c|}
\hline Operation Time & (hours/day) & 7.5 \\
\hline Total Break Time & (minutes/day) & 55 \\
\hline Walking Velocity for Mizusumashi & (meters/second) & 1 \\
\hline Production Speed & (minutes/piece) & $\operatorname{TRIA}(1,1.64,3.56)$ \\
\hline Number of Parts-storages & (sites) & 19 \\
\hline
\end{tabular}

In this period, one specific product is treated for analysis in spite of all three products being produced at the associated assembly line. The operation times and capacity of a container for 24 kinds of parts that used to assemble the selected product are shown in Table II. In Table II, $\operatorname{UNIF}(a, b)$ represents the uniform distribution with minimal value, $a$ and maximal value, $b$, and TRIA $(a, b, c)$ stands for the triangle distribution with minimal value, $a$, most likely value, $b$ and maximal value, $c$. Here, the value of disposal time is non-zero if the containers are made of cardboard and must be disposed. The zero values of filling time or supply time mean that certain improvements are implemented in order not to require specific associated operations.

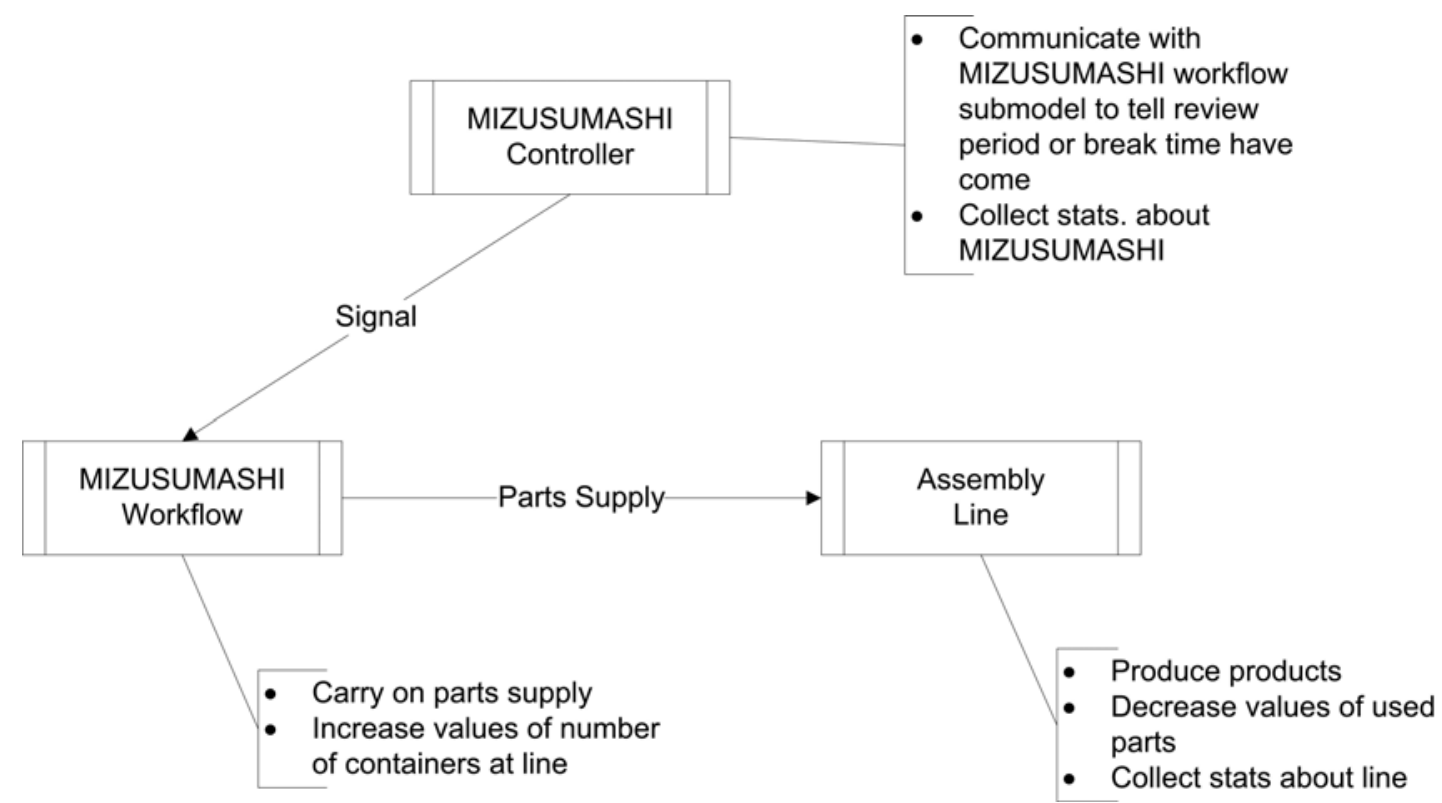

Figure 5: Simulation model structure. 
A simulation model of the system was constructed using Arena [12]. This simulation model was comprised of three submodels: the MIZUSUMASHI Controller, the MIZUSUMASHI Workflow and the Assembly Line submodels. The relationship among these submodels is illustrated in Fig. 5. The MIZUSUMASHI Controller submodel sends a signal to the Workflow submodel at each reviewing time. Receiving a signal, Mizusumashi workers carry on their consecutive operations of checking, disposing, filling and supplying parts. The Assembly Line submodel simulates the processing products and decreases values of used parts. Concerning the statistics, each lead time for the parts supply and utilization of the Mizusumashi were collected at the MIZUSUMASHI Controller submodel. The Assembly Line submodel records the production output, total times of parts shortages, and then repeats. An animation of the corresponding simulation model is shown in Fig. 6.

Table II: Working times and container capacity.

\begin{tabular}{|c|c|c|c|c|}
\hline $\begin{array}{c}\text { Part } \\
\text { ID }\end{array}$ & $\begin{array}{c}\text { Capacity for } \\
\text { a Container } \\
\text { (pieces) }\end{array}$ & $\begin{array}{l}\text { Filling Time } \\
\text { (seconds) }\end{array}$ & $\begin{array}{l}\text { Supply Time } \\
\text { (seconds) }\end{array}$ & $\begin{array}{l}\text { Disposal Time } \\
\text { (seconds) }\end{array}$ \\
\hline 1 & 3 & UNIF(33.71, 38.68) & UNIF(51.31, 60.28) & $\operatorname{UNIF}(5,8)$ \\
\hline 2 & 5 & $\operatorname{TRIA}(2,3,12)$ & $\operatorname{TRIA}(8,13.5,19)$ & UNIF(4.01, 13) \\
\hline 3 & 5 & $\operatorname{TRIA}(2,3,12)$ & $\operatorname{TRIA}(8,13.5,19)$ & UNIF(4.01, 13) \\
\hline 4 & 20 & UNIF $(3.53,6.16)$ & UNIF $(3.09,13)$ & 0 \\
\hline 5 & 20 & UNIF(8.61, 18.61) & UNIF(7.36, 17.36) & 0 \\
\hline 6 & 50 & $\operatorname{TRIA}(9.8,13.8,17.8)$ & UNIF(3.91, 13.91) & 0 \\
\hline 7 & 9 & UNIF(8.61, 18.61) & UNIF(7.36, 17.36) & 0 \\
\hline 8 & 20 & UNIF $(3.53,6.16)$ & UNIF $(3.09,13)$ & 0 \\
\hline 9 & 24 & UNIF(8.01, 18.01) & $\operatorname{TRIA}(8.8,12.8,16.8)$ & UNIF(7.66, 10.94) \\
\hline 10 & 25 & UNIF $(14,31)$ & $\operatorname{UNIF}(2.48,6.78)$ & 0 \\
\hline 11 & 25 & UNIF(14, 31) & $\operatorname{UNIF}(2.48,6.78)$ & 0 \\
\hline 12 & 90 & UNIF $(4.78,14.78)$ & UNIF(5.06, 15.06) & 0 \\
\hline 13 & 100 & UNIF(3.81, 13.81) & $\operatorname{TRIA}(38,42,44)$ & 0 \\
\hline 14 & 240 & $\operatorname{TRIA}(9.8,13.8,17.8)$ & UNIF(3.91, 13.91) & 0 \\
\hline 15 & 10 & UNIF(11.02, 16.03) & 0 & UNIF $(1.23,4.88)$ \\
\hline 16 & 4 & 0 & $\operatorname{TRIA}(8,10.4,17)$ & 0 \\
\hline 17 & 5 & UNIF $(4,5.21)$ & $\operatorname{TRIA}(2.15,4.42,4.55)$ & 0 \\
\hline 18 & 20 & UNIF(3.82, 13.82) & UNIF(67.22, 69.14) & UNIF $(9.96,10)$ \\
\hline 19 & 1 & 0 & UNIF $(4,13)$ & 0 \\
\hline 20 & 5 & $\operatorname{TRIA}(18.9,22.9,26.9)$ & UNIF(4.21, 6.21) & $\operatorname{UNIF}(1,10)$ \\
\hline 21 & 9 & $\operatorname{TRIA}(17.4,21.4,25.4)$ & UNIF(1.34, 6.47) & $\operatorname{UNIF}(1,10)$ \\
\hline 22 & 14 & UNIF(3.99, 13.99) & UNIF(1.71, 3.83) & 0 \\
\hline 23 & 20 & UNIF $(3.53,6.16)$ & UNIF $(3.09,13)$ & 0 \\
\hline 24 & 50 & $\operatorname{TRIA}(9.8,13.8,17.8)$ & UNIF(3.91, 13.91) & 0 \\
\hline
\end{tabular}




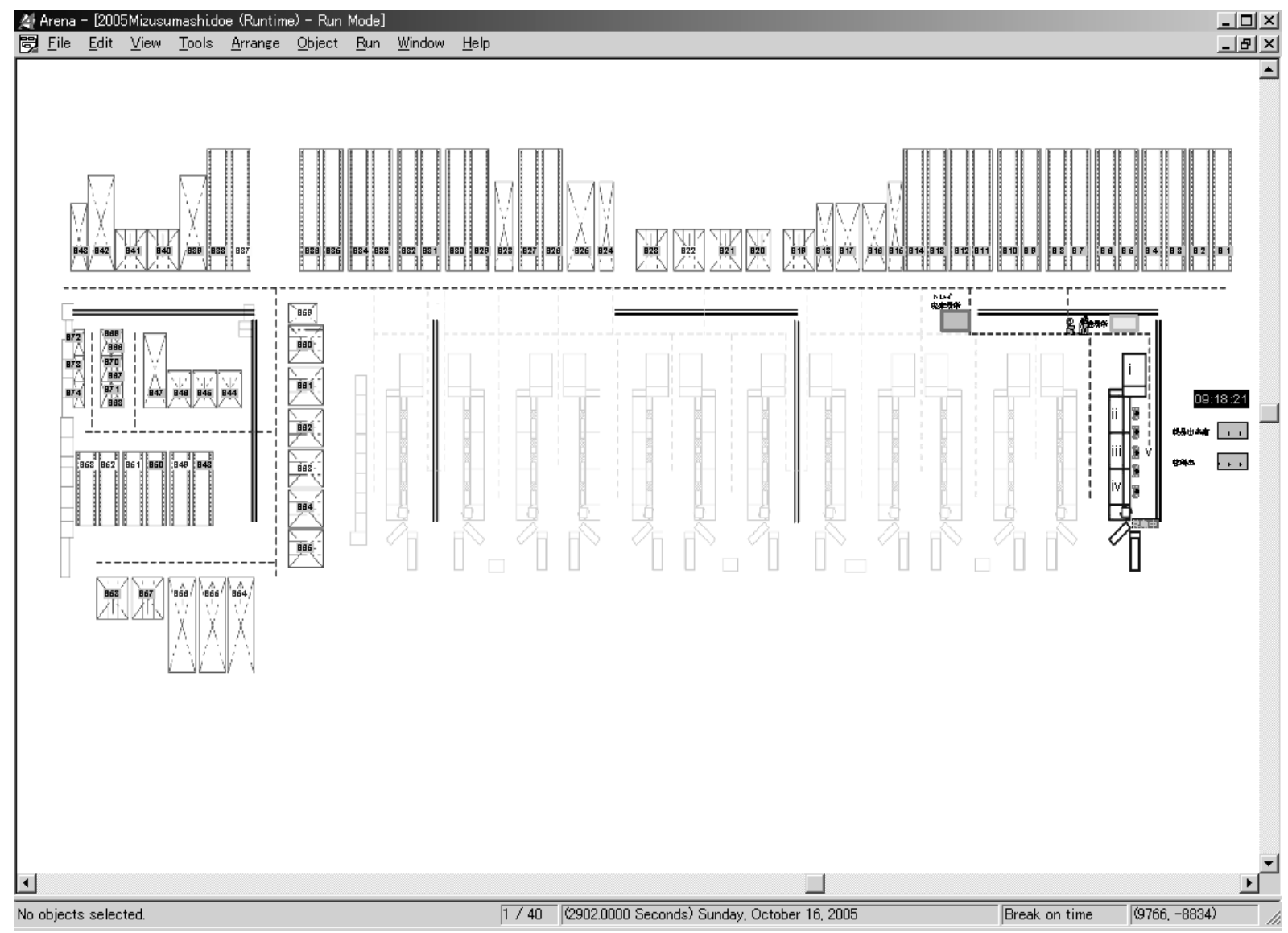

Figure 6: Animation of simulation model.

\section{PROCEDURE TO OBTAIN OPTIMAL NUMBERS OF PARTS-} CONTAINERS

The specific characteristics of a fixed-course pick-up system have been studied in our previous works [13]. A procedure is proposed to obtain optimal numbers of parts-containers, subject to the constraint on interruptions in the assembly process.

\subsection{Statement of the Problem}

In this study, the major concern is to obtain optimal numbers of parts-containers in the assembly process. In the general form of the model, the objective of the problem is to minimize the sum of the numbers of parts-containers, $x_{i}(i=1,2, \ldots, n)$ :

$$
\text { Minimize } y=\sum_{i=1}^{n} x_{i},
$$

subject to the constraints

$$
\begin{gathered}
f_{1}\left(x_{1}\right)=0, \\
: \\
f_{n}\left(x_{n}\right)=0,
\end{gathered}
$$

and the nonnegativity and integer conditions for $x_{i}(i=1,2, \ldots, n)$, where $f_{i}\left(x_{i}\right)(i=1,2, \ldots, n)$ stands for the average number of shortages (in times), and $i$ stands for part ID. 


\subsection{A Procedure}

As mentioned in the previous sections, a Mizusumashi worker does not usually supply the same parts over again, and the distance of the routing would vary. Consequently, the lead time between checking inventories and supplying parts varies each time. The estimated lead time should be determined to gain an understanding of the expected number of containers given by (1). In this context, the lead time could be estimated under some ideal conditions, by making use of simulation. After obtaining the estimated lead time, the expected number of containers can be obtained by (1) for each part to be used in the assembly line. Then, a simulation experiment can be executed to obtain the optimal solutions, by using these expected numbers of containers as a set of the initial conditions.

A heuristic procedure using a simulation experiment to seek the minimal or optimal number of containers for all associated parts is described as follows:

[Step 1] Set the sufficient numbers of containers. The values must be enough in order not to cause a parts shortage at the assembly line.

[Step 2] Set the time interval for the review period and execute a trial simulation-run to obtain the average time on the lead time for the parts supply.

[Step 3] By using (1), compute the expected number of containers for each part, and use them as the initial values for the simulation experiment carried out on Step 4.

[Step 4] Execute a simulation-run with conditions for the number of containers obtained on Step 3 or Step 5.

[Step 5] If parts shortages in the assembly lines are observed on this simulation-run, increment the number of containers causing interruptions in the assembly process and return to Step 4. Otherwise, go on to Step 6.

[Step 6] A set of the optimal number of each parts-container is obtained.

In Step 1, a set of the sufficient number of containers is determined in consideration of past experience or by an educated guess [14]. To use (1), the expected value of lead time and production speed should be obtained in advance. In the procedure, production speed can be obtained through such a method as time study, while the lead time for parts supply is obtained in Steps 1 and 2. It is important to set a sufficient number of containers and execute simulation-runs so that parts shortages never occur, and it leads to obtain an appropriate lead time. In Steps 4 through 6, increasing the numbers of containers caused parts shortages by one at one time, simulation will continue executing until parts shortage does not occur any more. Finally, the set of optimal number of containers are easily found.

\section{APPLICATIONS}

In this section, the proposed procedure is actually applied to the real manufacturing system described in Section 3 in order to confirm the effectiveness of this procedure from a practical standpoint.

The simulation model was developed for the system by adopting one Mizusumashi worker for supplying 24 kinds of parts onto an assembly line. According to the procedure, the first step required the setting of enough numbers in a series of containers so as to obtain the average value of lead time for the supply of parts. The sufficient numbers of containers were set as shown in Table III, according to Step 1 in the procedure. Setting each condition of a simulation-run to five operation days (7.5 hours/day) with one day warm-up and running 10 replications, the expected lead time was found to be $785.01 \pm 0.7$ seconds (a $95 \%$ significance level). Here, in this trial-simulation run, the time interval of the review period was set to 20 minutes and the expected production speed was 2.07 minutes (see Table I). 
Then, the values for the number of containers were computed by (1) for the initial conditions (See Table III, Iteration Number 1 and Column A). For example, six containers were obtained as the initial condition for Part ID 1.

Table III: Summary of results.

\begin{tabular}{|c|c|c|c|c|c|c|c|c|c|c|}
\hline \multirow{3}{*}{ Part ID } & \multirow{3}{*}{\begin{tabular}{|c|} 
Sufficient \\
Number of \\
Containers \\
(units)
\end{tabular}} & \multicolumn{8}{|c|}{ Iteration Number } & \multirow{3}{*}{$\begin{array}{c}\text { Optimal } \\
\text { Number of } \\
\text { Containers } \\
\text { (units) }\end{array}$} \\
\hline & & \multicolumn{2}{|c|}{1} & \multicolumn{2}{|c|}{2} & \multicolumn{2}{|c|}{3} & \multicolumn{2}{|c|}{4} & \\
\hline & & $A$ & B & $A$ & $B$ & $A$ & $B$ & A & $B$ & \\
\hline 1 & 11 & 6 & 0 & ditto & 0 & ditto & 0 & ditto & 0 & 6 \\
\hline 2 & 6 & 4 & 0 & ditto & 2.4 & 5 & 0 & ditto & 0 & 5 \\
\hline 3 & 6 & 4 & 0 & ditto & 2.6 & 5 & 0 & ditto & 0 & 5 \\
\hline 4 & 2 & 1 & 12 & 2 & 0 & ditto & 0 & ditto & 0 & 2 \\
\hline 5 & 2 & 1 & 12 & 2 & 0 & ditto & 0 & ditto & 0 & 2 \\
\hline 6 & 2 & 1 & 5 & 2 & 0 & ditto & 0 & ditto & 0 & 2 \\
\hline 7 & 5 & 2 & 3.1 & 3 & 1.5 & 4 & 0 & ditto & 0 & 4 \\
\hline 8 & 2 & 1 & 13 & 2 & 1.3 & 3 & 0 & ditto & 0 & 3 \\
\hline 9 & 2 & 1 & 10.1 & 2 & 0.3 & 3 & 0 & ditto & 0 & 3 \\
\hline 10 & 2 & 1 & 10 & 2 & 0.1 & 3 & 0 & ditto & 0 & 3 \\
\hline 11 & 2 & 1 & 10 & 2 & 0 & ditto & 0.2 & 3 & 0 & 3 \\
\hline 12 & 2 & 1 & 3 & 2 & 0 & ditto & 0 & ditto & 0 & 2 \\
\hline 13 & 2 & 1 & 3 & 2 & 0 & ditto & 0 & ditto & 0 & 2 \\
\hline 14 & 2 & 1 & 1 & 2 & 0 & ditto & 0 & ditto & 0 & 2 \\
\hline 15 & 3 & 2 & 0 & ditto & 0 & ditto & 0 & ditto & 0 & 2 \\
\hline 16 & 8 & 5 & 0 & ditto & 0.6 & 6 & 0 & ditto & 0 & 6 \\
\hline 17 & 6 & 4 & 0 & ditto & 4.1 & 5 & 0 & ditto & 0 & 5 \\
\hline 18 & 2 & 1 & 0 & ditto & 0 & ditto & 0 & ditto & 0 & 1 \\
\hline 19 & 30 & 17 & 0 & ditto & 0 & ditto & 0 & ditto & 0 & 17 \\
\hline 20 & 6 & 4 & 0 & ditto & 0.3 & 5 & 0 & ditto & 0 & 5 \\
\hline 21 & 5 & 2 & 1.9 & 3 & 0 & ditto & 0.1 & 4 & 0 & 4 \\
\hline 22 & 3 & 2 & 0 & ditto & 6.3 & 3 & 0 & ditto & 0 & 3 \\
\hline 23 & 2 & 1 & 13 & 2 & 0 & ditto & 0 & ditto & 0 & 2 \\
\hline 24 & 2 & 1 & 5 & 2 & 0 & ditto & 0 & ditto & 0 & 2 \\
\hline
\end{tabular}

A : Number of Containers (units) B : Average Number of Shortages (times)

The result of each simulation-run or iteration was summarized in Table III. The value in each Iteration Number and Column A signifies the number of containers used for this iteration and the average number of parts shortages is shown in Column $\mathrm{B}$ as the result of this simulation-run. If the average times of parts shortages were positive, parts shortages occurred in this simulation-run, and then, the corresponding number of parts-container should have increased by one at the next simulation-run. Now, take, as example, Part ID 2 to trace the execution of this procedure. In Step 1, sufficient numbers of containers for all parts were set 
from current shop floor settings, and six containers were set for Part ID 2. Proceeding to Step 2, the trial simulation-run was executed and the expected lead time was found. In Step 3, the required figures such as the expected lead time, production speed and container capacity were assigned to (1) in order to obtain the expected number of containers. The expected number of containers for Part ID 2 was obtained to be four, by substituting 785.01 (seconds) for the expected lead time, 2.07 (minutes) for the production speed, 20 (minutes) for the review period, and five (pieces) for the container capacity for Part ID 2 in (1), respectively (see Table II). Now, the number of containers obtained was the initial condition for the first simulationrun or iteration in Step 4; hence, four was shown in Table III, Iteration Number 1 and Column A. As the result of Iteration 1, shortages were observed on 14 kinds of parts, that is, Part ID 4 through 14, 21, 23 and 24, but no parts shortages was observed on Part ID 2. Hence, the same number of containers was used on this part for Iteration 2 (see the corresponding cells in Table III). This time, however, parts shortages resulted from Part ID 2 were occurred 2.4 times in Iteration 2. Then, the number of containers for Part ID 2 was incremented to five for executing simulation in Iteration 3. In Iterations 3 and 4, parts shortages come of Part ID 2 had never been observed and the optimal number of containers for Part ID 2 was found to be five.

By applying the proposed procedure, a set of the optimal numbers of containers is obtained after only four simulation-runs. The simulation results indicate that the proposed procedure contributes more smoothly and effectively in manufacturing activities in the sense of setting the minimal buffer space for parts inventories at the assembly line, while achieving the highest production rate without any interruptions caused by parts shortages.

\section{CONCLUSIONS}

The manufacturing assembly-line process known as a fixed-course pick-up (Mizusumashi) system was analyzed. The characteristics of the Mizusumashi system were described and the specific logic for building simulation models of a Mizusumashi system was presented. Furthermore, the specific equation used to obtain the expected number of the given container size was presented to show the initial conditions. Then, a heuristic procedure to determine the optimal number of containers was proposed with the help of simulation. In addition, the procedure was applied in a real manufacturing setting, and the proposed procedure was found to be effective and powerful especially from the practical standpoint.

\section{ACKNOWLEDGMENTS}

The authors wish to thank NEC AccessTechnica, Ltd. and Central Japan Industries Association (Chu-San-Ren) for their valuable suggestions.

\section{REFERENCES}

[1] Schonberger, R. (1982). Japanese Manufacturing Techniques: Nine Hidden Lessons in Simplicity, The Free Press, London

[2] Hernandez, A. (1989). Just-in-time Manufacturing: A practical Approach, Prentice-Hall, Inc., New Jersey

[3] Hitomi, K. (1996). Manufacturing Systems Engineering (2nd Edition), Taylor \& Francis, London

[4] Fujimoto, T. (1999). The Evolution of a Manufacturing System at Toyota, Oxford University Press, New York

[5] Schniederjans, M. J.; Olson, J. R. (1999). Advanced Topics in Just-in-time Management, Quorum Books, Westport 
[6] Arnold, J. R.; Chapman, S. N. (2001). Introduction to Materials Management (4th Edition), Prentice-Hall, Inc., New Jersey

[7] Askin, R. G.; Goldberg, J. B. (2002). Design and Analysis of Lean Production Systems, John Wiley \& Sons, Inc., New York

[8] Gross, J. M.; Mcinnis, K. R. (2003). Kanban Made Simple: Demystifying and Applying Toyota's Legendary Manufacturing Process, Amacom, New York

[9] Nomura, J.; Takakuwa, S. (2004). Module-based modeling of flow-type multistage manufacturing systems adopting dual-card Kanban system, Proceedings of 2004 Winter Simulation Conference, (eds) M. D. Rossetti, et al., 1065-1072

[10] Monden, Y. (1998). Toyota Production System: An Integrated Approach to Just-In-Time (3rd Edition), Engineering \& Management Press, Norcross

[11] Lewis, C. D. (1970). Scientific Inventory Control, Butterworths, London

[12] Kelton, W. D.; Sadowski, R. P.; Sturrock, D. T. (2004). Simulation with Arena (3rd Edition), McGraw-Hill, New York

[13] Nomura, J. (2005). Simulation Analysis on Management Systems of Just-in-time Manufacturing, Ph. D. Dissertation (in Japanese), Nagoya University, 41-58

[14] Takakuwa, S.; Nomura, J. (2003). Optimization and analysis of Mizusumashi systems as just-intime manufacturing, Annals of DAAAM for 2003 \& Proceedings of the 14th International DAAAM Symposium, (Ed.) B. Katalinic, 461-462 